\title{
The effect of the SAFE or SORRY? programme on patient safety knowledge of nurses in hospitals and nursing homes: A cluster randomised trial
}

\author{
Betsie G.I. van Gaal a,*, Lisette Schoonhoven ${ }^{\mathrm{a}}$, Lilian C.M. Vloet ${ }^{\mathrm{b}, \mathrm{c}}$, Joke A.J. Mintjes ${ }^{\mathrm{c}, \mathrm{d}}$, \\ George F. Borm ${ }^{\mathrm{e}}$, Raymond T.C.M. Koopmans ${ }^{\mathrm{f}}$, Theo van Achterberg ${ }^{\mathrm{a}}$ \\ ${ }^{\text {a }}$ Scientific Institute for Quality of Healthcare, Radboud University Nijmegen Medical Centre, Nijmegen, The Netherlands \\ ${ }^{\mathrm{b}}$ Teaching Hospital, Canisius Wilhelmina Hospital, Nijmegen, The Netherlands \\ ${ }^{\mathrm{c}}$ Faculty of Health and Social Studies, HAN University of Applied Sciences, Nijmegen, The Netherlands \\ ${ }^{\mathrm{d}}$ CEO Netherlands Centre for Excellence in Nursing, Utrecht, The Netherlands \\ ${ }^{\mathrm{e}}$ Department of Epidemiology, Biostatistics and HTA, Radboud University Nijmegen Medical Centre, Nijmegen, The Netherlands \\ ${ }^{\mathrm{f}}$ Department of Primary and Community Care, Centre for Family Medicine, Geriatric Care and Public Health Medicine, Radboud University Nijmegen Medical Centre, \\ Nijmegen, The Netherlands
}

\section{A R T I C L E I N F O}

\section{Article history:}

Received 30 July 2009

Received in revised form 3 February 2010

Accepted 6 February 2010

\section{Keywords:}

Education

Hospitals

Long term care

Multicentre studies

Nurses

Safety management

\begin{abstract}
A B S T R A C T
Background: Patients in hospitals and nursing homes are at risk for the development of often preventable adverse events. Guidelines for the prevention of many types of adverse events are available, however compliance with these guidelines appears to be lacking. As a result many patients do not receive appropriate care. We developed a patient safety program that allows organisations to implement multiple guidelines simultaneously and therefore facilitates guideline use to improve patient safety. This program was developed for three frequently occurring nursing care related adverse events: pressure ulcers, urinary tract infections and falls. For the implementation of this program we developed educational activities for nurses as a main implementation strategy.

Objectives: The aim of this study is to describe the effect of interactive and tailored education on the knowledge levels of nurses.

Design: A cluster randomised trial was conducted between September 2006 and July 2008. Settings: Ten hospital wards and ten nursing home wards participated in this study. Prior to baseline, randomisation of the wards to an intervention or control group was stratified for centre and type of ward.

Participants: All nurses from participating wards.

Methods: A knowledge test measured nurses' knowledge on the prevention of pressure ulcers, urinary tract infections and falls, during baseline en follow-up. The results were analysed for hospitals and nursing homes separately.

Results: After correction for baseline, the mean difference between the intervention and the control group on hospital nurses' knowledge on the prevention of the three adverse events was 0.19 points on a zero to ten scale (95\% CI: -0.03 to 0.42 ), in favour of the intervention group. There was a statistically significant effect on knowledge of pressure ulcers, with an improved mean mark of 0.45 points (95\% CI: $0.10-0.81$ ). For the other two topics there was no statistically significant effect. Nursing home nurses' knowledge did neither improve ( 0 points, $\mathrm{Cl}$ : -0.35 to 0.35 ) overall, nor for the separate subjects.
\end{abstract}

\footnotetext{
* Corresponding author at: Scientific Institute for Quality of Healthcare, Radboud University Nijmegen Medical Centre, 114 IQ healthcare, P.O. Box 9101, 6500 Nijmegen, The Netherlands. Tel.: +31 24 3619326; fax: +31243540166.

E-mail address: B.vangaal@iq.umcn.nl (Betsie G.I. van Gaal).
} 
Conclusion: The educational intervention improved hospital nurses' knowledge on the prevention of pressure ulcers only. More research on long term improvement of knowledge is needed.

Trial registration: ClinicalTrials.gov ID [NCT00365430].

(c) 2010 Elsevier Ltd. All rights reserved.

\section{What is already known about the topic?}

- Knowledge among health care workers is a prerequisite, along with insight and skills, for any implementation process.

- The effects of passive education, written material and large-scale educational meetings, are often limited.

\section{What this paper adds}

- Tailored interventions and interactive, personalised education do not guarantee long term improvement of nurses' knowledge on common adverse events and how to prevent them.

- Hospital and nursing home nurses score too low on knowledge to be able to provide sufficiently safe care in the prevention of common adverse events.

\section{Introduction}

\subsection{Background}

Recent studies showed that patients in hospitals and nursing homes are at risk for the development of, often preventable, adverse events (Thomas et al., 2000) (Table 1). An adverse event is defined as "an unintended injury that results in prolonged stay, disability at the time of discharge, or death and is caused by health care management rather than by the patient's underlying disease process" (Thomas et al., 2000).

Although many guidelines are available, compliance with these guidelines appears to be lacking (Grol, 2001; Schuster et al., 1998; Halfens and Eggink, 1995). As a result, many patients receive inappropriate care (Grol and Grimshaw, 2003). Generally, many factors or barriers may influence compliance - or noncompliance - with a guideline (Grol and Grimshaw, 2003). These general barriers may be related to the individual (e.g. knowledge, skills, attitudes, motivation) or the individual's social context (e.g. patients, colleagues, culture), and the organisational setting (e.g. financial, equipment) (Grol and Wensing, 2004). Moreover, the large number of guidelines competing for attention makes it difficult to keep track of all of them. In addition organisations must translate each guideline to their own target group, and develop and organise their own information and education, which is a time-consuming process. All this combined makes it difficult for organisations to implement all relevant guidelines. This situation is at odds with the responsibility of professionals to ensure patient safety. To facilitate hospital and nursing home organisations in guideline implementation, we developed a patient safety program (SAFE or SORRY?) that allows organisations to implement multiple guidelines simultaneously (Van Gaal et al., 2009). We developed this program for three frequently occurring nursing care related adverse events, for which guidelines on preventive care are available: pressure ulcers, urinary tract infections and falls. For the implementation of this patient safety program we developed educational activities as a main implementation strategy.

Education is a necessary component of any implementation strategy (Wensing and Grol, 2005) and can lead to changes in professional behaviour (Grol and Grimshaw, 2003), although the effects of most types of education are small (Grol and Grimshaw, 2003). In general, passive approaches (written material and large-scale educational meetings) are ineffective and unlikely to result in behaviour change (Grimshaw et al., 2001). To improve the effectiveness of an educational strategy, the activities should have specific characteristics (Grimshaw et al., 2001). Education that is interactive and personal, such as small-scale educational meetings and educational outreach visits, is more effective (Grol and Grimshaw, 2003). Therefore we developed interactive and personal educational activities which were tailored to the needs of the nursing ward. Subsequently, we assessed the effect of this educational implementation strategy on nurses' knowledge.

In this article we will describe the effect of interactive and tailored education on the knowledge levels of the nurses.

\section{Methods}

\subsection{Design and settings}

The study was embedded in the SAFE or SORRY? study, which is a cluster randomised trial (Van Gaal et al., 2009)

Table 1

Definitions.

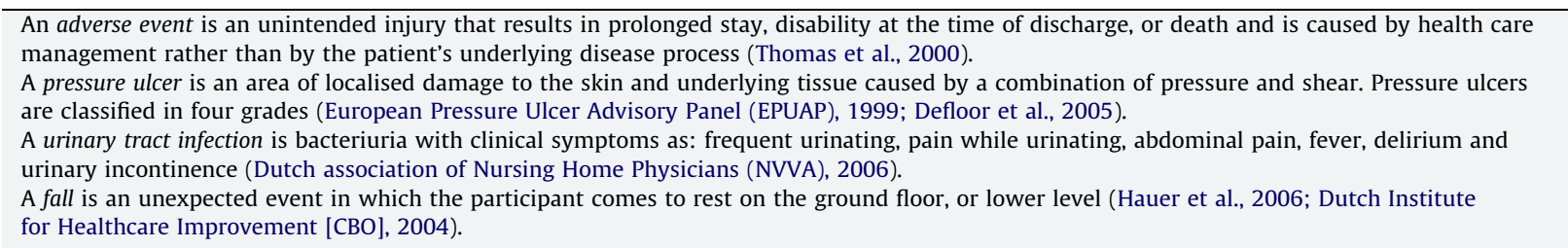


The effectiveness of our educational intervention was tested within this trial. In a cluster randomised trial, groups of individuals rather than individuals are randomised (Campbell and Grimshaw, 1998). In our study the intervention involved the entire team of nurses and not individual nurses on nursing wards. Therefore nurses within the same ward were considered to be a cluster (Campbell and Grimshaw, 1998). The current study was conducted between September 2006 and July 2008. It included a purposive sample of 20 wards from four hospitals (one university hospital, two large teaching hospitals and one small hospital) and six nursing homes in the Netherlands. Hospitals and nursing homes were asked to participate with two or four, more or less comparable wards. The hospital wards were internal medicine wards $(n=4)$ and surgical wards $(n=6)$. The nursing home wards were wards with patients with physical impairments (no dementia) $(n=7)$ and rehabilitation wards $(n=3)$. The randomisation of the wards was stratified for centre and type of ward and took place prior to baseline data collection (Fig. 1). The baseline period was in September 2006 and follow-up measurement was performed from May to July 2008, 1 year after the end of the intervention period. Five hospital wards and five nursing home wards were randomised to the intervention group.

\subsection{Outcome}

The score on a test regarding the three topics: pressure ulcers (European Pressure Ulcer Advisory Panel (EPUAP), 1999; Defloor et al., 2005), urinary tract infections (Dutch association of Nursing Home Physicians (NVVA), 2006) and falls (Hauer et al., 2006; Dutch Institute for Healthcare Improvement [CBO], 2004).

\subsection{Data collection}

All registered and licensed nurses working within the 20 participating wards were invited to participate in the study. Data were collected using questionnaires. At each ward, one nurse was responsible for the distribution and collection of the questionnaires.

\subsection{Development of the questionnaire}

The questionnaire contained a knowledge test and seventeen demographic questions: e.g. age, gender, work experience on the present ward. The knowledge test contained 20 statements per topic, addressing aetiology of the adverse events, risk assessment and preventive care. With each statement, nurses could answer 'correct', 'incorrect', or 'do not know'. The test was based on existing knowledge tests (Defloor and Dehoucke, 2002; Van der Kolk and Schuurmans, 2002; Schoonhoven et al., 2004; Geriatric Nursing Association, 2007) and tests on the three adverse events used at the HAN University of Applied Sciences. The face validity was tested by sending the knowledge test to the members of the research group (LS, JM, RK and TvA), and an additional expert per topic. Based on their feedback, we changed suggestive statements into more objective statements and reformulated statements that were considered too easy. Finally, we asked four

\section{HOSPITALS}

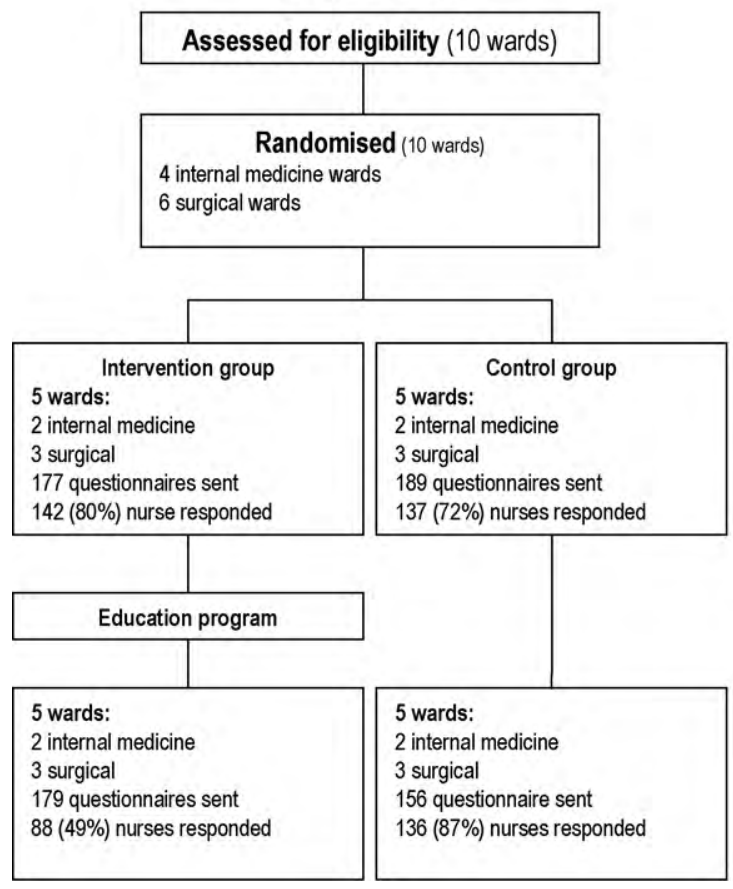

\section{NURSING HOMES}

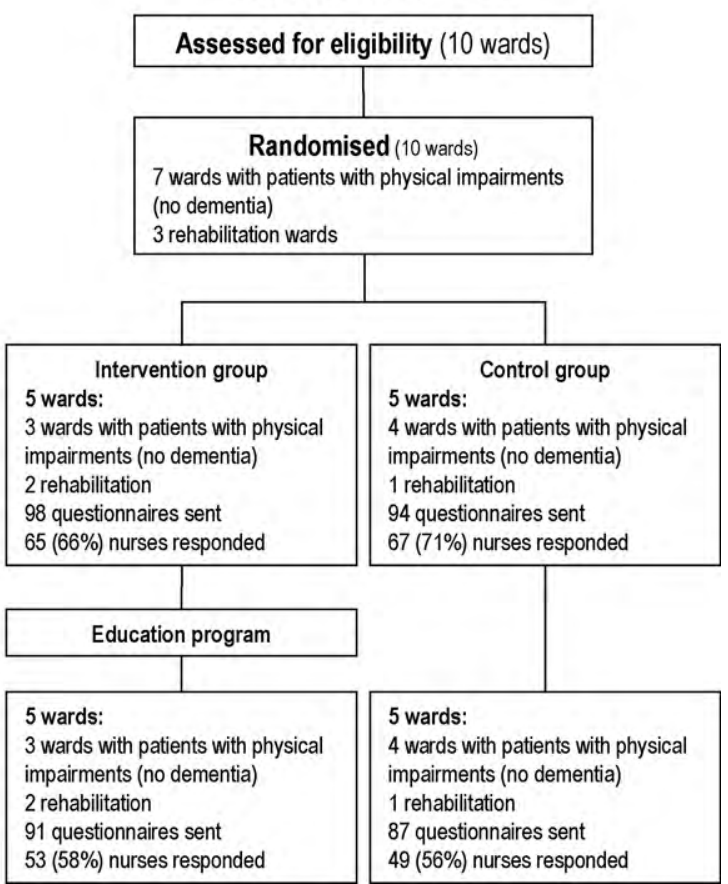

Fig. 1. Flow diagram. 
nurses in hospitals and nursing homes to pretest the knowledge test. No changes were made after this test.

\subsection{Intervention}

The nurses from the intervention wards received the educational interventions of the patient safety program between December 2006 and June 2007. Nurses from the control wards did not receive educational interventions.

The content of the educational intervention was based on the existing guidelines for the prevention of pressure ulcers, urinary tract infections and falls; (Dutch association of Nursing Home Physicians (NVVA), 2006; Dutch Institute for Healthcare Improvement [CBO], 2004; Dutch Institute for Healthcare Improvement [CBO], 2002; Dutch Workingparty on Infection Prevention (WIP), 2005a; Dutch Workingparty on Infection Prevention (WIP), 2005b) and supplementary material (Defloor et al., 2005; Dutch association of Nursing Home Physicians (NVVA), 2003; Gillespie, 2004; Schoonhoven et al., 2006) and tailored to each individual ward. The education consisted of small-scale educational meetings, educational materials and outreach visits. The development of this intervention was described in an earlier article (Van Gaal et al., 2009).

The implementation period started with two to three small-scale educational meetings $(1.5 \mathrm{~h})$. All nurses had to attend one meeting. The main subjects during these meetings were: causes of adverse events, assessment of patients at risk for adverse events and how to prevent the adverse events. After 2-3 months, every ward planned two case discussions ( $30 \mathrm{~min}$ ). During these case discussions the nurses and the researcher reviewed patients on their ward regarding the causes of adverse events, assessment of risk for adverse events and preventive care.

The educational material consisted of an educational compact disc for every ward. Besides the theoretical items (causes of the adverse events, assessment of patients at risk and prevention of adverse events) a test with feedback (for nurses to test their own knowledge) was included. At most wards the educational compact disc was copied onto the desktop of the computer, allowing nurses to look up the information during their work. Where this was not possible, the nurses received a copy of the compact disc and took it home.

Additionally, every intervention ward appointed two key nurses to the study. Together with the ward manager they were responsible for the implementation of the intervention on their ward. In the hospitals these key nurses were all registered nurses. In the nursing homes key nurses were registered and licensed nurses. They all received training in managing the different types of educational interventions. Also, the result of the baseline test was discussed and all educational activities on the wards were planned and organised. During the intervention period the researcher planned two outreach visits ( $5 \mathrm{~h}$ ) with key nurses at every ward for training on the job. The key nurses had periodical contact with the researcher about the progress of the intervention.

\subsection{Ethical considerations}

The local Medical Ethics Committee assessed the study and waived the need for complete evaluation of the study. The anonymity of both the wards and the nurses in the hospitals and nursing homes was assured. Ref. No.: CMO nr: 2005/121.

\subsection{Statistical analysis}

For the current study, all nurses working on the participating wards during baseline and follow-up, were invited to participate. In the Netherlands the majority of the hospital nurses are bachelor or registered nurses, while in nursing homes very few bachelor or registered nurses are employed. Here, the majority of the nurses are licensed nurses. Because nurses' characteristics differ between hospitals and nursing homes, the data were analysed for hospital wards and nursing home wards separately. With the knowledge test, every correct answer scored one point, every incorrect answer scored minus one point and the "do not know' answers and omitted answers were given zero points. To calculate an overall mark for the three topics we first added up the scores for each topic to obtain a number between -20 and 20 . Second, to get a mark between 0 and 10 we calculated as follows: (the result of a topic +20 )/4. Third, the overall mark was subsequently calculated in the following way: (mark pressure ulcers + mark urinary tract infections + mark falls $) / 3$.

We used a linear random effects model to analyse the difference in the results on the knowledge test between the intervention and the control wards at follow-up. This model was used because of the hierarchical structure of the data (nurses were clustered within wards. Data were analysed with the baseline values as covariate, centre as fixed factor and ward as random factor. Ninety-five percent confidence intervals were calculated and results were considered significant if the confidence interval did not include zero.

\section{Results}

\subsection{Hospitals}

In hospitals, 503 nurses (72\%) returned the knowledge test. The response rate in all groups was high (>70\%) with the exception of the intervention group at follow-up (49\%) (Table 2), yet in each group every ward had an equal percentage of nurses who returned the questionnaire. The mean age of the nurses was 38 years $(S D=10.7)$ and 411 (89\%) were females. There were no differences in hospital nurses' characteristics between the intervention and the control group at baseline or follow-up (Table 2).

At follow-up, multilevel analysis showed that for the intervention group the mean overall mark on the knowledge of the three adverse events improved with 0.19 points (on a zero to ten scale). However, this improvement was statistically non-significant ( $95 \% \mathrm{CI}$ : -0.03 to 0.42 ). The knowledge on two topics (urinary tract infections and pressure ulcers) showed a positive trend in favour of the intervention group (Table 4). Improved knowledge on 
Table 2

Characteristics of hospital nurses.

\begin{tabular}{|c|c|c|c|c|}
\hline \multirow[t]{2}{*}{ Hospitals } & \multicolumn{2}{|l|}{ Baseline } & \multicolumn{2}{|l|}{ Follow-up } \\
\hline & Intervention & Control & Intervention & Control \\
\hline$N$ & 142 & 137 & 88 & 136 \\
\hline Age mean year (SD) & $37.0(9.9)$ & $38.2(11.3)$ & $36.9(10.0)$ & $38.1(11.5)$ \\
\hline Female & $119(92)$ & $109(87)$ & $76(91)$ & $107(85)$ \\
\hline \multicolumn{5}{|l|}{ Highest education } \\
\hline Primary school & $1(1)$ & $1(1)$ & 0 & 0 \\
\hline Secondary school & $63(50)$ & $61(48)$ & $41(53)$ & $57(46)$ \\
\hline High school & $63(50)$ & $62(49)$ & $36(47)$ & $64(52)$ \\
\hline University & 0 & $2(2)$ & 0 & $2(2)$ \\
\hline \multicolumn{5}{|l|}{ Position on ward } \\
\hline Bachelor nurses & $59(42)$ & $67(50)$ & $36(41)$ & $66(49)$ \\
\hline Registered nurses & $80(57)$ & $66(49)$ & $50(57)$ & $67(50)$ \\
\hline Licensed nurses & $2(1)$ & $2(2)$ & $2(2)$ & $1(1)$ \\
\hline \multicolumn{5}{|l|}{ Work experience } \\
\hline Current ward mean year (SD) & $8.8(7.6)$ & $8.4(7.0)$ & $9.4(7.9)$ & $8.4(7.5)$ \\
\hline Work hours/week & $26.2(8.1)$ & $27.2(7.2)$ & $27.1(7.6)$ & $28.8(6.4)$ \\
\hline \multicolumn{5}{|c|}{ Post-registration education last 3 year } \\
\hline Pressure ulcers & $64(45)$ & $74(55)$ & $48(55)$ & $53(39)$ \\
\hline Urinary tract infections & $1(1)$ & $5(4)$ & $17(20)$ & $13(10)$ \\
\hline Falls & $22(20)$ & $12(9)$ & $20(23)$ & $13(10)$ \\
\hline
\end{tabular}

Values represent number (percentages) unless stated otherwise.

pressure ulcers was statistically significant ( 0.45 points (95\% CI: 0.10-0.81)).

\subsection{Nursing homes}

In nursing homes $234(63 \%)$ nurses returned the knowledge test. The response rate at baseline was higher (69\%) than at follow-up (57\%). The mean age of the nurses was 39 years $(S D=10.2)$ and $214(96 \%)$ were females.
There were no differences in nurses' characteristics for the intervention and the control group at either baseline or follow-up (Table 3).

At follow-up, multilevel analysis showed no difference in the mean overall mark between the intervention and the control group (Table 4). The knowledge on one topic improved in the intervention group $(0.17$ points $(95 \% \mathrm{CI}$ : -0.31 to 0.65$)$ ) on a zero to ten scale, however this improvement was statistically non-significant.

Table 3

Characteristics of nursing home nurses.

\begin{tabular}{|c|c|c|c|c|}
\hline \multirow[t]{2}{*}{ Nursing homes } & \multicolumn{2}{|l|}{ Baseline } & \multicolumn{2}{|l|}{ Follow-up } \\
\hline & Intervention & Control & Intervention & Control \\
\hline$N$ & 65 & 67 & 53 & 49 \\
\hline Age mean year (SD) & $38.1(10.0)$ & $38.4(10.0)$ & $41.3(10.3)$ & $37.4(10.1)$ \\
\hline Female & $58(97)$ & $59(95)$ & $45(98)$ & $43(94)$ \\
\hline \multicolumn{5}{|l|}{ Highest education } \\
\hline Primary school & $4(7)$ & $2(3)$ & 0 & $1(3)$ \\
\hline Secondary school & $49(85)$ & $53(90)$ & $38(88)$ & $32(84)$ \\
\hline High school & $5(9)$ & $4(7)$ & $5(12)$ & $4(11)$ \\
\hline University & 0 & 0 & 0 & $1(3)$ \\
\hline \multicolumn{5}{|l|}{ Position on ward } \\
\hline Bachelor nurses & 0 & 0 & $1(2)$ & $1(2)$ \\
\hline Registered nurses & $13(21)$ & $13(20)$ & $7(14)$ & $11(22)$ \\
\hline Licensed nurses & $49(79)$ & $51(80)$ & $43(84)$ & $37(76)$ \\
\hline \multicolumn{5}{|l|}{ Work experience } \\
\hline Current ward mean year (SD) & $9.0(7.8)$ & $7.2(5.8)$ & $7.4(7.5)$ & $6.9(5.8)$ \\
\hline Work hours/week & $24.5(8.9)$ & $25.8(8.0)$ & $24.5(7.8)$ & $26.4(8.1)$ \\
\hline \multicolumn{5}{|c|}{ Post-registration education last 3 year } \\
\hline Pressure ulcers & $15(23)$ & $28(42)$ & $25(48)$ & $17(36)$ \\
\hline Urinary tract infections & $8(13)$ & $5(8)$ & $21(41)$ & $4(9)$ \\
\hline Falls & $6(9)$ & $5(8)$ & $17(33)$ & $4(9)$ \\
\hline
\end{tabular}

Values represent numbers (percentages) unless stated otherwise. 
Table 4

Mean marks of nurses' knowledge in hospitals and in nursing homes.

\begin{tabular}{|c|c|c|c|c|c|c|}
\hline \multirow[t]{2}{*}{ Hospitals } & \multicolumn{2}{|l|}{ Baseline } & \multicolumn{2}{|l|}{ Follow-up } & \multirow{2}{*}{$\begin{array}{l}\text { Estimate } \\
\text { a }\end{array}$} & \multirow{2}{*}{$\begin{array}{l}95 \% \mathrm{CI} \\
\mathrm{a}\end{array}$} \\
\hline & Intervention & Control & Intervention & control & & \\
\hline Overall & $6.8(0.60)$ & $6.9(0.57)$ & $7.2(0.78)$ & $7.1(0.64)$ & 0.19 & -0.03 to 0.42 \\
\hline Pressure ulcers & $5.4(0.95)$ & $5.7(0.94)$ & $6.0(1.10)$ & $5.7(0.99)$ & 0.45 & 0.10 to 0.81 \\
\hline Urinary tract infections & $7.1(0.78)$ & $7.1(0.85)$ & $7.4(0.95)$ & $7.3(0.87)$ & 0.15 & -0.15 to 0.45 \\
\hline Falls & $7.9(0.88)$ & $7.9(0.90)$ & $8.3(1.03)$ & $8.2(0.87)$ & -0.03 & -0.35 to 0.29 \\
\hline \multirow[t]{2}{*}{ Nursing homes } & \multicolumn{2}{|l|}{ Baseline } & \multicolumn{2}{|l|}{ Follow-up } & Estimate & $95 \% \mathrm{CI}$ \\
\hline & Intervention & Control & Intervention & control & $\mathrm{a}$ & a \\
\hline Overall & $6.4(0.73)$ & $6.1(0.58)$ & $6.7(0.81)$ & $6.4(0.67)$ & 0.00 & -0.35 to 0.35 \\
\hline Pressure ulcers & $5.0(0.84)$ & $4.8(0.78)$ & $5.4(0.96)$ & $5.1(0.76)$ & -0.05 & -0.48 to 0.39 \\
\hline Urinary tract infections & $6.9(0.97)$ & $6.5(0.89)$ & $7.1(0.97)$ & $6.6(0.94)$ & 0.17 & -0.31 to 0.65 \\
\hline Falls & $7.3(1.23)$ & $7.1(1.05)$ & $7.7(1.23)$ & $7.6(1.13)$ & -0.12 & -0.71 to 0.48 \\
\hline
\end{tabular}

Values represent mean marks (std. dev.) unless stated otherwise.

a Results from multilevel analysis.

\section{Discussion en conclusion}

This study showed that the educational intervention of the patient safety program did not improve nurses' knowledge on the three adverse events in hospitals and nursing homes. There was a small positive overall effect on hospital nurses' knowledge, but this effect was statistically non-significant and too small to be relevant for daily practice. Of the three topics, only the knowledge on pressure ulcers showed a statistically significant improvement that is also relevant for daily practice. For the other topics there were no effects. Nursing home nurses' knowledge on the three adverse events did not improve. Of the three topics, the knowledge of urinary tract infections showed a small improvement, but this effect was statistically non-significant and too small to be relevant for daily practice.

To appreciate our results some aspects need to be discussed. For this study we wanted to develop an effective educational intervention. Therefore, we avoided passive education (written material and large-scale educational meetings), because this kind of education is less effective than education which is interactive and personal (Grimshaw et al., 2001; Grol and Grimshaw, 2003). For that reason our educational intervention employed small-scale educational meetings, which were all interactive and tailored to the wards (Van Gaal et al., 2009). We further developed an interactive compact disc with an additional knowledge test to avoid written and standard material. Also the outreach visits had an interactive and personal character.

While many studies describe the effectiveness of an educational intervention to change health care professional practice and behaviours (Freemantle et al., 2000; Jamtvedt et al., 2006; O'Brien et al., 2007; Farmer et al., 2008; Reeves et al., 2008; Gagnon et al., 2009; Forsetlund et al., 2009), fewer studies describe the effectiveness of an educational intervention on knowledge of health care professionals (Brimmer et al., 2008; Chan et al., 2009; Gunningberg, 2004; Wallace et al., 2006). Most of these pre- and post-test studies on knowledge did describe an increase of knowledge, but none of these studies had a control group. Moreover, knowledge was usually mea- sured immediately after the intervention. One study measured knowledge at intervals, i.e. immediately after the intervention, 3 months and 6 months after the intervention (Chan et al., 2009). This study showed that indeed there was an increase of knowledge immediately and 3 months after the intervention, but the positive changes did not sustain for more than 6 months (Chan et al., 2009). This could be a possible explanation for the lack of significant increase in knowledge in our study, as our follow-up measurement took place one and a half year after the start of the educational intervention. Unfortunately, we could not measure knowledge at intervals, because our evaluation was part of a larger study (Van Gaal et al., 2009) and measuring knowledge at intervals could have caused bias in other outcomes. In this light, the positive effect on hospital nurses' knowledge of pressure ulcers might even imply that the increase in nurses' knowledge is a long term improvement, which is promising for further development of this educational intervention. However, more research into the short- and long term effects of this type of education is needed.

Another explanation for the limited effects could lie in the knowledge test. We chose to use a self-constructed knowledge test because we did not find an existing test that fitted our intervention. Although good knowledge tests are available for each of the topics separately, there was no test that addressed all topics simultaneously. Combining three existing knowledge tests would have resulted in too many questions. Moreover, as the existing knowledge tests focussed on both prevention and treatment, we would have posed irrelevant questions, as our intervention focussed on prevention only. Therefore, we selected the relevant questions on the prevention of the three adverse events from several sources and constructed our own knowledge test. Unfortunately we were not able to fully validate the self-constructed knowledge test. While we did test the face validity in an expert panel, we did not extensively assess the knowledge test in our population. We were concerned that we developed a knowledge test too difficult for nursing home nurses, but the results showed that nursing home nurses had more or less comparable marks for the tests in relation to the 
hospital nurses. However, we did not test the responsiveness. Possibly, this could have biased our results.

There are a few methodological issues which should be considered. First there is the issue of data collection. In our study it was not possible to fill in the knowledge test under exam conditions. Despite the fact that the wards were asked to organise these exam conditions they did not succeed in doing so. It is possible that nurses who received the knowledge test looked up the answers, e.g. on the internet, or in a protocol, or that they asked each other for the correct answers. Therefore it is possible that the results of our study are biased. To avoid this type of bias in future studies, it is advisable to organise exam condition when filling in this kind of knowledge test.

Another methodological consideration is that fewer nurses returned the knowledge test during the follow-up period, hospital nurses in the intervention group especially. We assume that these nurses were less motivated, due to the higher turnover rate of the hospital nurses (in two hospitals) and the extra workload for the nurses that came with this study. Possibly, nurses who had affinity with the subject were more likely to respond. This may have resulted in selection bias, as we do not know whether the nurses were representative for the nurses of their ward. We do know that every ward had an equal percentage of nurses who returned the questionnaire. In nursing homes more nurses with a lower position on the ward (licensed nurses) returned the questionnaire at follow-up in the intervention group compared to the control group, which could explain the lower result at follow-up for the intervention group in nursing homes.

We did not systematically measure staff turnover, but we know from the periodic contact with the key nurse and ward manager on the intervention wards, that nurses had left and other nurses were employed. Consequently, staff turnover may have influenced the results of this study especially given the length of time to follow-up. To minimise this kind of influence, 'new' nurses who were employed on the ward after the educational interventions, were offered the opportunity to access the educational information about the patient safety programme by using the CD-ROM with the theoretical items and the tests with feedback. The key nurse and ward manager on the intervention wards were responsible for acquainting 'new' nurses with the patient safety programme.

The follow-up of this study took place one and a half year after the start of the intervention period. This long period potentially opened the study up to external influences. If hospitals and nursing homes decided to start special quality improvement programs on one of our adverse events for instance this would have influenced our results. To monitor for this kind of influence, we interviewed every ward manager (intervention and control wards) about (their plans to organise) educational activities on the three adverse events prior to baseline and follow-up measurement. We were able to prevent that two hospitals organised separate courses on the subject of falls. Instead they organised courses on other important subjects (delirium and use of restraints). From the inventory we know that there were no educational activities on our three adverse events.
As we studied different wards in the same centre, contamination across wards could have occurred. However, we are convinced that contamination is not an issue in our study. First, we agreed with the intervention wards that the educational material (CD-ROM) could only be used by the intervention wards, and the other educational activities (educational meetings and case discussions) were only organised for the nurses of the intervention wards, other nurses were not invited. Thus, the control wards did not have access to the educational material and did not know the content of the educational activities. We promised the control wards that they would receive the educational activities (if they wanted) after the study. Second, although nurses from the intervention ward (occasionally) worked on the control ward and vice versa, this only occurred in one hospital ward and in one nursing home ward. Moreover, when nurses did work across wards this was due to nursing shortage, which means that there was not much time for extra activities, as all time was needed for the most essential/basic activities such as taking care of the patient (washing, eating). Therefore, there would not have been much time to discuss issues from the education and contamination was unlikely.

A last methodological consideration is the sensitivity of our test. Ninety-five percent of the scores in hospitals were between 5.6 and 8.0 and between 5.0 and 7.6 in nursing homes. There was not much variation, as all the scores were between 5.0 and 8.0, which corresponds to $25 \%$ of our total scale (a zero to ten scale). This might indicate that our scale was not sensitive enough to measure improvements.

There are a few recommendations we want to make. First, knowledge about the content of a guideline is an important prerequisite for the use of a guideline. In this study the mean score on guideline related knowledge was a seven (on a zero to ten scale). We consider this score to be too low, and take the view that a nine is the minimally desired score, because if nurses have insufficient knowledge of a guideline they cannot give appropriate care. Second, to improve this knowledge our interactive and personal educational intervention should become a continuous activity (Grol and Grimshaw, 2003). Since acquired knowledge will not sustain overtime (Chan et al., 2009), education should be a continuous activity to guarantee a long term effect on knowledge. Third, we suggest to develop a web based learning/training program (instead of a CD-ROM) including a knowledge test with personal feedback on the results (Grol and Grimshaw, 2003). A web based program makes it possible for ward managers (or teachers) to identify the nurses who have or have not studied the information and give the individual nurse and the whole team feedback on the results and their performance. Finally, we recommend to measure the effect of such an intervention at intervals, in order to capture both short- and long term improvements.

In conclusion, we found a long term effect of our educational intervention on hospital nurses' knowledge on the prevention of pressure ulcers only. It is possible that there were short term effects, but we did not measure these. More research is necessary to expand this educational intervention so it can have a long term effect on nurses knowledge. 
Conflict of interest: The authors declare they have no competing interests.

Authors' contributions: BvG wrote the article, developed the educational intervention and the knowledge test, collected and analysed the data. LS developed the idea and the design of this study, wrote the article, has been involved in the development of the educational intervention and in the development of the knowledge test, and is the supervisor of the study. LV has been involved in the development of the educational intervention and revised the article. JM developed the idea and the design of this study, has been involved in the development of the educational intervention and in the development of the knowledge test, and revised the article. GB is the statistician and has been involved in the design of the study, supervised the analyses of the study and revised the article. RK developed the idea and the design of this study, has been involved in the development of the educational intervention and in the development of the knowledge test and revised the article. TvA developed the idea and the design of this study, has been involved in the development of the educational intervention and in the development of the knowledge test, is the general supervisor of the study and revised the article.

All authors approved the final version of the manuscript.

Funding: The Netherland Organisation for Health Research and Development (ZonMW) funded and approved the design of this study [ID: 54010002]. This funding organisation did not have any role in the selection of the hospitals or nursing homes; the collection, analysis and interpretation of the data; the writing of the report or the decision to submit this paper for publication.

\section{References}

Brimmer, D.J., McCleary, K.K., Lupton, T.A., Faryna, K.M., Hynes, K., Reeves, W.C., 2008. A train-the-trainer education and promotion program: chronic fatigue syndrome-a diagnostic and management challenge. BMC Med. Educ. 8, 49.

Campbell, M.K., Grimshaw, J.M., 1998. Cluster randomised trials: time for improvement. The implications of adopting a cluster design are still largely being ignored. BMJ 317 (7167), 1171-1172.

Chan, S.W., Chien, W.T., Tso, S., 2009. Evaluating nurses' knowledge, attitude and competency after an education programme on suicide prevention. Nurse Educ. Today 29 (7), 763-769.

Defloor, T., Dehoucke, J., 2002. Decubitus [pressure ulcers]. In: Van Achterberg, T., Eliens, A.M., Strijbol, N.C.M. (Eds.), Effectief Verplegen 1: Handboek ter onderbouwing van het verpleegkundig handelen. (Effective Nursing 1: Handbook Evidence for Nursing Care).Kavanah, Dwingeloo, pp. 123-156.

Defloor, T., Herremans, A., Grypdonck, M.H., De Schuijmer, J.D., Paquay, L., Schoonhoven, L., Vanderwee, K., Bours, G., Cuyvers, A., De Laat, E., Feyaerts, S., Demaiter, G., Haalboom, J., Halfens, R., Heyman, H., Van Kol, E., Weststraete, J., 2005. Belgium Guideline Prevention of Pressure Ulcers. Academia Press, Gent.

Dutch Institute for Healthcare Improvement [CBO], 2002. Second revision pressure ulcers. Downloaded May 2005; available from: http://www.cbo.nl/product/richtlijnen/folder20021023121843/ decubitus2002.pdf? (only in Dutch).

Dutch Institute for Healthcare Improvement [CBO], 2004. Guidelines 'Fall Prevention in the Elderly'. Van Zuiden Communications BV, Alphen aan den Rijn.

Dutch Association of Nursing Home Physicians (NVVA), 2003. Tripartite Multidisciplinary Guideline: Collaboration and Logistic Process of Pressure Ulcers. Beroepsvereniging van verpleeghuisartsen en geriaters (NVVA), Utrecht.
Dutch association of Nursing Home Physicians (NVVA), 2006. Guideline Urinary Tract Infections. Beroepsvereniging van verpleeghuisartsen en geriaters (NVVA), Utrecht.

Dutch Workingparty on Infection Prevention (WIP), 2005a. Definitions hospital infections. Leyden University Medical Center, Leiden.

Dutch Workingparty on Infection Prevention (WIP), 2005b. Prevention of Infection as a Result of Urinary Catheterisation Via the Urethra. Leyden University Medical Center, Leiden.

European Pressure Ulcer Advisory Panel (EPUAP), 1999. Guidelines on Treatment of Pressure Ulcers. EPUAP Review 1. , pp. 31-33.

Farmer, A.P., Legare, F., Turcot, L., Grimshaw, J., Harvey, E., McGowan, J.L. Wolf, F., 2008. Printed educational materials: effects on professional practice and health care outcomes. Cochrane Database Syst. Rev. 3, CD004398.

Forsetlund, L., Bjorndal, A., Rashidian, A., Jamtvedt, G., O'Brien, M.A., Wolf, F., Davis, D., Odgaard-Jensen, J., Oxman, A.D., 2009. Continuing education meetings and workshops: effects on professional practice and health care outcomes. Cochrane Database Syst. Rev. 2, CD003030.

Freemantle, N., Harvey, E.L., Wolf, F., Grimshaw, J.M., Grilli, R., Bero, L.A., 2000. Printed educational materials: effects on professional practice and health care outcomes. Cochrane Database Syst. Rev. 2, CD000172.

Gagnon, M.P., Legare, F., Labrecque, M., Fremont, P., Pluye, P., Gagnon, J., Car, J., Pagliari, C., Desmartis, M., Turcot, L., Gravel, K., 2009. Interventions for promoting information and communication technologies adoption in healthcare professionals. Cochrane Database Syst. Rev. 1, CD006093.

Geriatric Nursing Association, 2007. Geriatric Educational Material. V\&VN Geriatrie Verpleegkunde, Utrecht.

Gillespie, L., 2004. Preventing falls in elderly people. BMJ 328 (7441), 653654.

Grimshaw, J.M., Shirran, L., Thomas, R., Mowatt, G., Fraser, C., Bero, L., Grilli, R., Harvey, E., Oxman, A., O'Brien, M.A., 2001. Changing provider behavior: an overview of systematic reviews of interventions. Med. Care 39 (8 Suppl. 2), II2-45.

Grol, R., 2001. Successes and failures in the implementation of evidencebased guidelines for clinical practice. Med. Care 39 (8 Suppl. 2), II46II54.

Grol, R., Grimshaw, J., 2003. From best evidence to best practice: effective implementation of change in patients' care. Lancet 362 (9391), 12251230.

Grol, R., Wensing, M., 2004. What drives change? Barriers to and incentives for achieving evidence-based practice. Med. J. Aust. 180 (6 Suppl.), S57-S60.

Gunningberg, L., 2004. Pressure ulcer prevention: evaluation of an education programme for Swedish nurses. J. Wound Care 13 (3), 85-89.

Halfens, R.J., Eggink, M., 1995. Knowledge, beliefs and use of nursing methods in preventing pressure sores in Dutch hospitals. Int. J. Nurs. Stud. 32 (1), 16-26.

Hauer, K., Lamb, S.E., Jorstad, E.C., Todd, C., Becker, C., 2006. Systematic review of definitions and methods of measuring falls in randomised controlled fall prevention trials. Age Ageing 35 (1), 5-10.

Jamtvedt, G., Young, J.M., Kristoffersen, D.T., O’Brien, M.A., Oxman, A.D. 2006. Audit and feedback: effects on professional practice and health care outcomes. Cochrane Database Syst. Rev. 2, CD000259.

O’Brien, M.A., Rogers, S., Jamtvedt, G., Oxman, A.D., Odgaard-Jensen, J., Kristoffersen, D.T., Forsetlund, L., Bainbridge, D., Freemantle, N., Davis, D.A., Haynes, R.B., Harvey, E.L., 2007. Educational outreach visits: effects on professional practice and health care outcomes. Cochrane Database Syst. Rev. 4, CD000409.

Reeves, S., Zwarenstein, M., Goldman, J., Barr, H., Freeth, D., Hammick, M., Koppel, I., 2008. Interprofessional education: effects on professiona practice and health care outcomes. Cochrane Database Syst. Rev. 1, CD002213.

Schoonhoven, L., Van Kol, E., Defloor, T., Grypdonck, M.F., 2004. Implementation of a Research Based Pressure Ulcer Guideline: A Study in Nursing Homes. , Utrecht.

Schoonhoven, L., Grobbee, D.E., Donders, A.R., Algra, A., Grypdonck, M.H. Bousema, M.T., Schrijvers, A.J., Buskens, E., 2006. Prediction of pressure ulcer development in hospitalized patients: a tool for risk assessment. Qual. Saf. Health Care 15 (1), 65-70.

Schuster, M.A., McGlynn, E.A., Brook, R.H., 1998. How good is the quality of health care in the United States? Milbank Q. 76 (4) 509, 517-63.

Thomas, E.J., Studdert, D.M., Burstin, H.R., Orav, E.J., Zeena, T., Williams, E.J., Howard, K.M., Weiler, P.C., Brennan, T.A., 2000. Incidence and types of adverse events and negligent care in Utah and Colorado. Med. Care 38 (3), 261-271.

Van der Kolk, R., Schuurmans, M., 2002. Verwardheid [Delirium]. In: Van Achterberg, T., Eliens, A.M., Strijbol, N.C.M. (Eds.), Effectief Verplegen 1: Handboek ter onderbouwing van het verpleegkundig handelen. 
(Effective Nursing 1: Handbook Evidence for Nursing Care).Kavanah, Dwingeloo, pp. 443-477.

Van Gaal, B.G.I., Schoonhoven, L., Hulscher, M.E.J.L., Mintjes, J.A.J., Borm, G.F., Koopmans, R.T.C.M., Van Achterberg, T., 2009. The design of the SAFE or SORRY? study: a cluster randomised trial on the development and testing of an evidence based inpatient safety program for the prevention of adverse events. BMC Health Serv. Res. 9 (1), 58.
Wallace, M., Greiner, P., Grossman, S., Lange, J., Lippman, D.T., 2006. Development, implementation, and evaluation of a geriatric nurse education program. J. Contin. Educ. Nurs. 37 (5), 214-217.

Wensing, M., Grol, R., 2005. Educational interventions. In: Grol, R., Wensing, M., Eccles, M. (Eds.), Improving Patient Care: The implementation of Change in Clinical Practice. Elsevier, London, pp. 147157. 